\title{
Influence of Particle Concentration and Type on Flow, Thermal, and Mechanical Properties of Wood-Polypropylene Composites
}

\author{
Lei Xie, ${ }^{1, *}$ Timo Grueneberg,${ }^{2}$ Leif Steuernagel, ${ }^{1}$ Gerhard Ziegmann ${ }^{1}$ \\ AND HOLGER MILITZ ${ }^{2}$ \\ ${ }^{1}$ Institute of Polymer Materials and Plastics Engineering, Clausthal University \\ of Technology, Clausthal-Zellerfeld, Germany \\ ${ }^{2}$ Department of Wood Biology and Wood Products, University of Goettingen, \\ Goettingen, Germany
}

\begin{abstract}
Two kinds of wood particles with different sizes and properties were compounded with polypropylene (PP) in highly concentrated levels (by 50\% and 60\% weight concentration). Their flow abilities were estimated by viscosity-shear rheological test and spiral flow mold respectively; the results show that higher concentrations result in poor flow ability. However, to estimate the relation between particle size and flow ability, spiral flow-mold testing results are not consistent with those of the rheological test. The thermal melting, crystallization, and stability of the highly filled wood/PP composites were measured by differential scanning calorimetry (DSC). The results clearly showed that the melting temperature, thermal stability, and crystalline degree of composites decrease when filler contents and size increase. The mechanical properties of these materials were assessed by tensile test machine and testing results also show that the filler concentration and size dramatically affect the mechanical properties, such as E module, tensile strength, and breaking strength of wood-particle-filled PP composites. The weld-line strength of all wood composites with the contents was also tested in the same way. By testing, one found that the usual defect of weld line in injection-molding process had a very significant negative impact on the mechanical properties of wood composites and the relation of wood-particle-filling fraction and size to weld-line strength was also analyzed and clarified.
\end{abstract}

KEY WORDS: wood particles, polypropylene, flow ability, mechanical property, thermal property weld line.

\section{INTRODUCTION}

D UE TO THE primary advantages of their low cost, low density, biodegradability, recyclability, and resistance to breakage during processing, wood fillers (wood fiber, wood flour, wood particles, etc.) have been applied to reinforce polymer material since the 1980s. Nowadays, wood plastic composites can be found in many application fields, like machine manufacture, automobile, house decoration, and construction industry [1-7]. This field is

*Author to whom correspondence should be addressed. E-mail: Lei.Xie@tu-clausthal.de

Figures 3-9 appear in color online: http://jrp.sagepub.com

Journal of Reinforced Plastics And COMPosites, Vol. 29, No. 13/2010 
drawing more and more attention in the world and many meaningful research achievements have been presented about the investigation on factors related to mechanical properties, physical and thermal properties, and rheological properties [8-15]. Lyons and Ahmed [16] analyzed the effects of resin system, wood-surface condition, moisture content, primer application, and environmental exposures on bond strength, for composites made by hand-layup with two types of epoxies and E-glass fabric on seven different yellow pine wood surfaces. Cantero et al. [17] studied the effects of wood treatment on the mechanical properties of composites made with wood flour and polypropylene (WF/PP). Kaboorani and Faezipour [18] treated wood at different temperatures $\left(175^{\circ} \mathrm{C}, 190^{\circ} \mathrm{C}\right.$, and $\left.205^{\circ} \mathrm{C}\right)$ and the results showed that thermal instability was caused by the introduction of wood to the composites. Composites consisting of different amounts of wood and coupling agent and HDPE were produced by the injection-molding method. The mass loss measured by thermogravimetric analysis (TGA) was used as a tool to evaluate thermal stability of the materials. Cui et al. [19] produced wood fiber-reinforced, recycled plastic composites (WRPCs) from saw dust and post-consumer high-density polyethylene (HDPE) and studied the thermal, flexural properties, and impact strength of the manufactured WRPCs according to the relevant standard specifications. Effects of mix ratio, wood-fiber length, type, and content of coupling agent on the mechanical properties of WRPCs were also investigated. Chaharmahali et al. [20] manufactured wood plasticcomposite (WPC) panels with HDPE, MDF, and particle-board waste at 60,70 , and $80 \mathrm{wt} \%$ fiber loadings using the dry blend/hot press method. Physical and mechanical properties of the panels were studied and compared with conventional MDF and particle-board panels. Azizi and Ghasemi [21] investigated the rheological behavior of polypropylene wood flour (WF) composite and showed that it was at constant temperature over a wide range of frequencies using a mechanical compact rheometer operated in the dynamic mode. The effect of WF content, particle size, and coupling agent on melt rheological properties were also studied. Hristov and Vlachopoulos [22] investigated the influence of polymer matrix molecular weight and filler particle size on rheological properties and extrudate distortions of metallocene polyethylene (mPE)/WF composites using rotational and capillary rheometers. It was found that at low shear rates, smaller filler particles provide higher shear viscosity than the larger-sized filler. At high shear rates, andWF loadings above $30 \mathrm{wt} \%$, the effect of particle size on the melt flow properties becomes negligible. Nourbakhsh and Ashoriz [23] studied the effect of wood fiber concentrations and mixing temperature on the mechanical properties of composites, prepared by using maleic anhydride polypropylene (MAPP) as the coupling agent and the results showed that the fiber loading of 30 and $40 \mathrm{wt} \%$ at $190^{\circ} \mathrm{C}$ provided adequate reinforcement to increase the tensile and flexural strength of the PP powder. The modulus also increased with increasing the fiber contents. Migneault et al. [24] researched the correlation of processing method and fiber size with the properties of WPC. Composites were manufactured using extrusion or injection molding (IM) and fibers of different fiber lengthto-diameter $(L / D)$ ratio. IM resulted in better mechanical properties and lower water absorption and swelling than extrusion. These differences can be explained by the structure and surface quality of the composites. Fiber $L / D$ ratio had a beneficial effect on mechanical properties but resulted in decreased water-absorption characteristics. Beg and Pickering [25] described the effects of reprocessing on the physical and mechanical properties of composites based on radiata pine (Pinus radiata) fiber in a PP matrix. For composites with $40 \mathrm{wt} \%$ fiber, tensile strength (TS) and Young's modulus (YM) were found to decrease with increased reprocessing by up to $25 \%$ for TS and $17 \%$ for YM (after reprocessed eight times). Flexural tests were also carried out for $40 \mathrm{wt} \%$ fiber composites and flexural strength 
and modulus were found to decrease with increased reprocessing. Dominkovics et al. [26] showed that the surface of wood flour used as reinforcement in $\mathrm{PP} /$ wood composites was successfully modified by benzylation in $\mathrm{NaOH}$ solution of $20 \mathrm{wt} \%$ concentration at $105^{\circ} \mathrm{C}$. Based on the literature reviewed in the last two decades, the works which systemically study the effects of wood filler types on WPC properties in the highly filled concentration are limited. In this study, two different wood particles are compounded with PP in $50 \%$ and $60 \%$ by weight. The flow ability, thermal property, mechanical property, and the injection molded weld-line strength of the wood polymer composites produced are supposed to be investigated systemically. The correlation between particle type, filling contents, and these measured properties will be found out.

\section{EXPERIMENTAL}

\section{Materials}

Two kinds of wood particles were chosen as the reinforcing filler in this study (from J.Rettenmaier \& Sohne GMBH + Co). One was softwood Type 9 (LIGNOCEL ${ }^{\circledR}$ ) with particle size $0.8 \mathrm{~mm}-1.1 \mathrm{~mm}$ and the other was raw cellulose Type C100 (ARBOCEL ${ }^{\circledR}$ ) with particle size $70 \mu \mathrm{m}-150 \mu \mathrm{m}$. The detail specific features of both particles are listed in Table 1. The polymer matrix was PP from DOW Europe GmbH (DOW C705-44) which has high MFI $44\left(190^{\circ} \mathrm{C} 2.6 \mathrm{~kg} / 10 \mathrm{~min}\right)$.

\section{Composites Compounding}

Two wood particles with $4.5 \%$ moisture were compounded with PP by an extrusion machine (Leistritz Micro27), with 10 temperature-controlling zones. The temperature setting for each zone is shown in Figure 1. The extruder rotation speed was set at $150 \mathrm{rpm}$ during compounding. Composites with $50 \%$ and $60 \%$ wood particles by weight are separately prepared for the two types.

After compounding, the composites were granulated by the chopper machine and ground to finer granulates for use in injection-molding process.

\section{Property Measuring Equipments}

For flow ability experimental, two methods were employed: one was rotation rheometer test for shear-rate/viscosity relation and the other was the spiral mold for material flow length test. Rotation rheometer (TA Instrument) can measure the viscosity in the

Table 1. The specific features of the wood particles used in the presented study.

\begin{tabular}{lccccc}
\hline Particle type & Color & Structure & Size range $(\mathrm{mm})$ & Bulk density $(\mathbf{g} / \mathrm{L})$ & Ignition \\
\hline 9 & Yellow & Cubic & $0.8-1.1^{\mathrm{a}}$ & $140-210$ & $850^{\circ} \mathrm{C} 4 \mathrm{~h} 0.5 \%$ \\
C100 & Beige & Cubic & $0.07-0.15^{\mathrm{b}}$ & $140-180$ & $850^{\circ} \mathrm{C} 4 \mathrm{~h} 0.5 \%$ \\
\hline
\end{tabular}

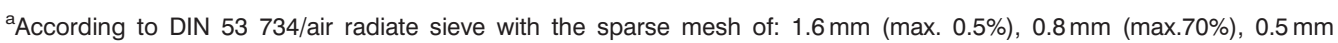
(max. 99\%).

${ }^{\circ}$ According to DIN 53 734/air radiate sieve with the sparse mesh of: $250 \mu \mathrm{m}$ (max. $0.5 \%$ ), $100 \mu \mathrm{m}$ (max. $45 \%$ ), $32 \mu \mathrm{m}$ (max. 95\%). 
frequency range from 0 to 1000 angle frequency. The spiral mold was manufactured according to ASTM D3123 (98). The flow-length tests were done at different mold temperatures and melt temperatures, and the correlation between flow ability and temperatureprocessing parameters was discussed.

For mechanical property test, a multi-functional test machine Zwick ${ }^{\circledR}$ was used to do the tensile test for the samples by the EN ISO Standard 527-2:1996; its main dimensions are illustrated in Figure 2. The weld-line strength measurement was also implemented in this machine using the same dimensional tensile samples but with weld lines.

For thermal property measuring, DSC from TA Instrument was applied to investigate the composite's thermal stability, crystallites, and change of melting temperature.

\section{Samples Preparation}

In order to test the mechanical property of the composites compounded, an injection molding tool for tensile sample preparation was fabricated according to ISO standard EN ISO Standard 527-2:1996. This tool is with double gates which makes it possible to produce tensile sample with and without weld line by a changeable ejector for blocking one gate or not. Then the weld line strength test sample also can be molded and studied for the composites. The rotational rheometer measuring specimens were also prepared by injection molding process. The sample has the same dimension as the rheometer holder (diameter $25 \mathrm{~mm}$ ), and the thickness is $1 \mathrm{~mm}$, shown in Figure 3. These sample-preparation processes were carried out on a horizontal injection-molding machine Arburg $220 \mathrm{~s}^{\circledR}$, which has a screw with $15-\mathrm{mm}$ diameter and can supply $150 \mathrm{KN}$ maximum clamping force and $250 \mathrm{MPa}$ maximum injection pressure.

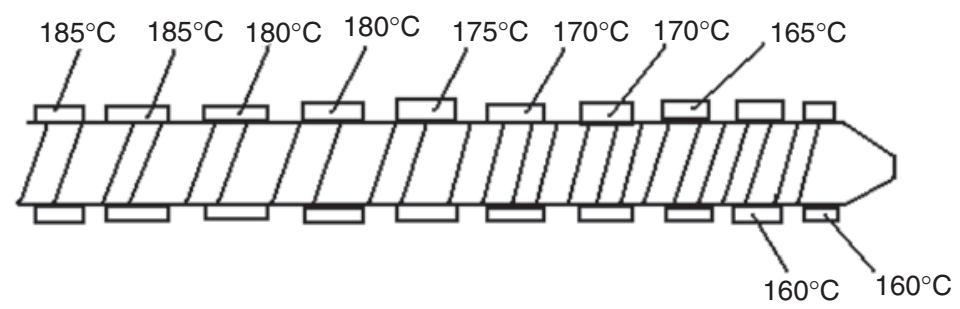

Figure 1. Temperature setting in different zones of extrusion machine.

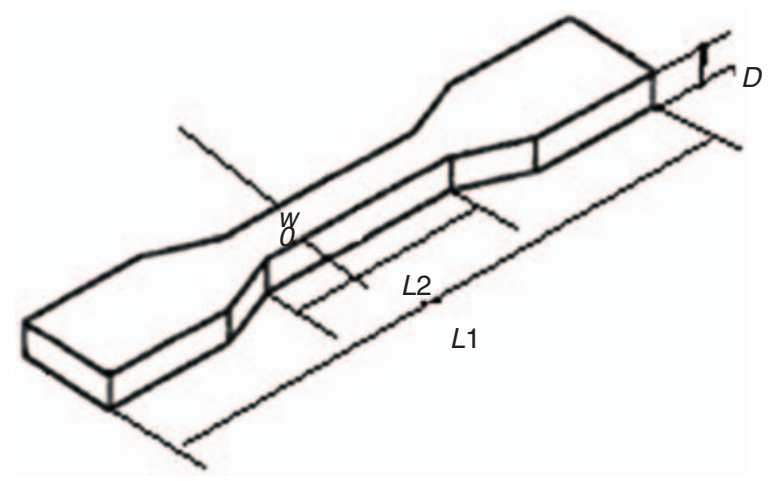

Figure 2. The dimension of the tensile test sample $(L 1=30 \mathrm{~mm} ; L 2=12 \mathrm{~mm} ; W=2 \mathrm{~mm} ; D=2 \mathrm{~mm})$. 
The rheological data of the composites were measured by the rotation rheometer at $200^{\circ} \mathrm{C}$, and results are shown in Figure 4.

Based on the test results, it can be concluded that in the high concentration of wood particles, wood PP composites have much higher viscosity than the pure PP. With the increasing

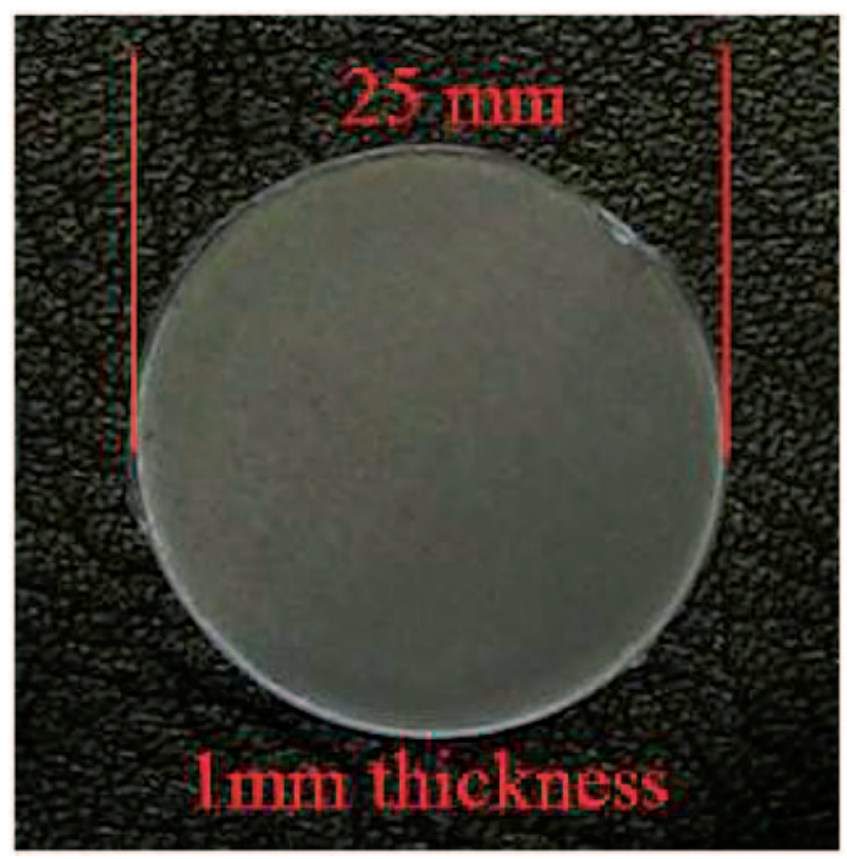

Figure 3. Geometry and dimensions of rheometer test samples.

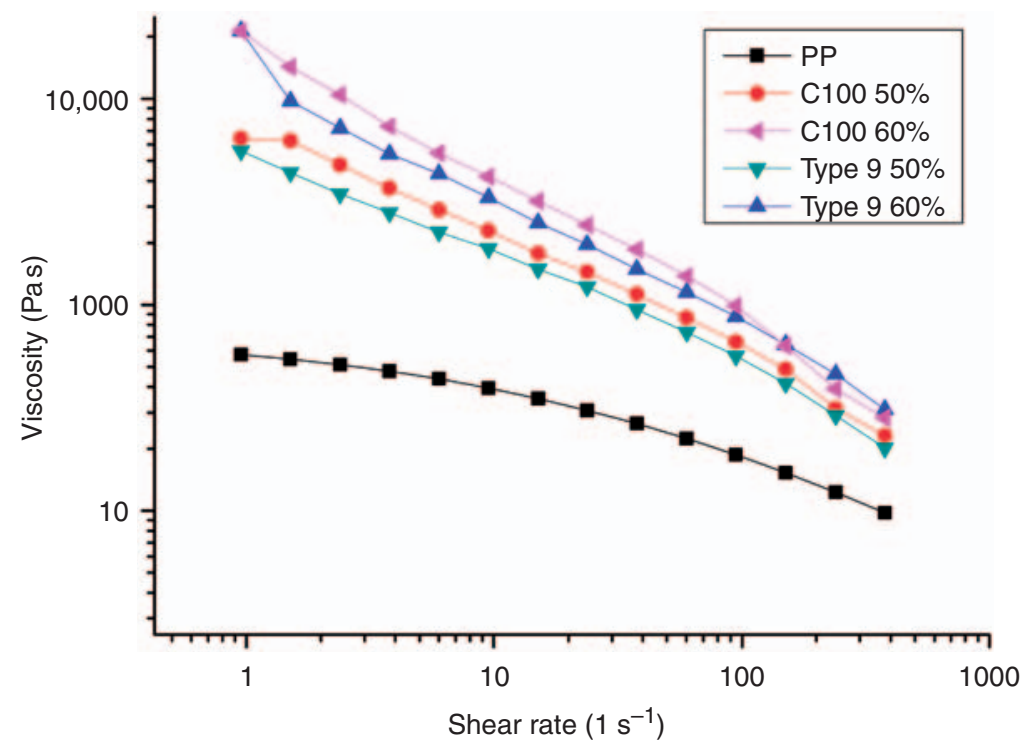

Figure 4. Viscosity vs shear rate plots for wood/pp composites with different wood particles contents. 

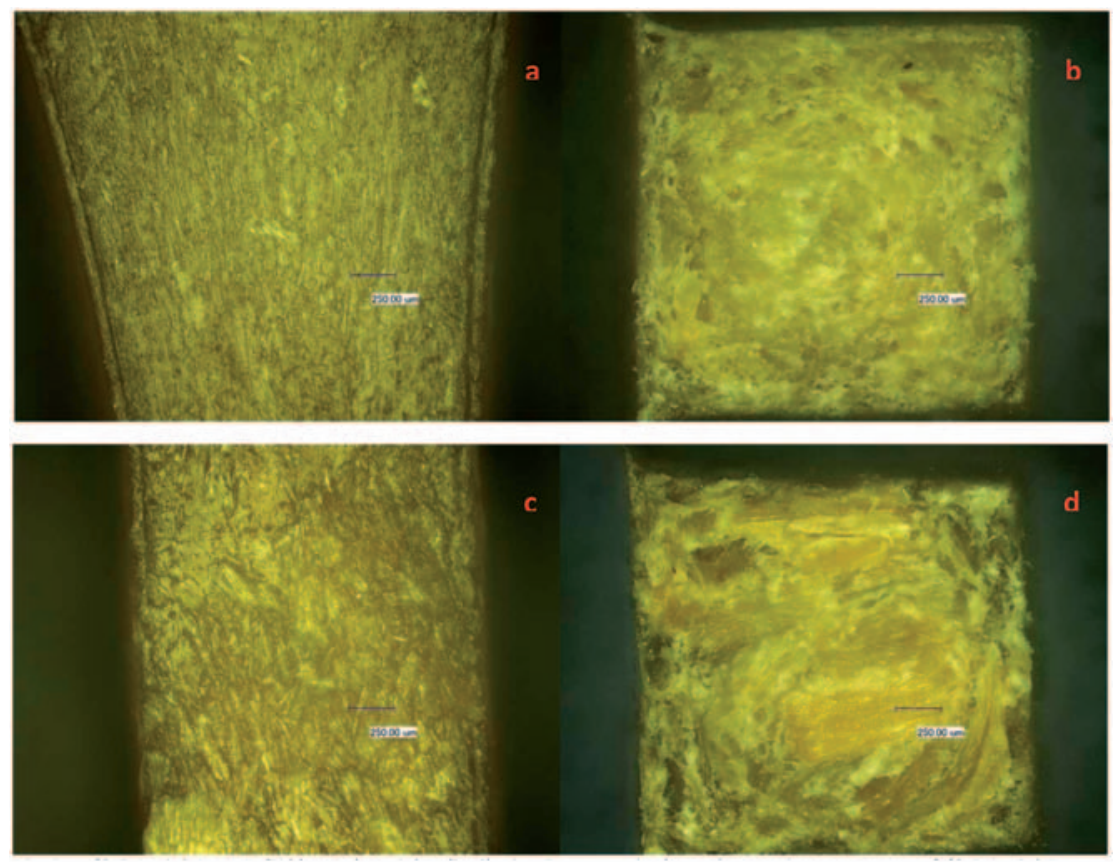

Figure 5. (a) $60 \%$ (weight) Type C100 wood particles distribution in PP matrix, (b) broken section appearance of 60\% (weight) type C100 wood/PP composites, (c) 60\% (weight) Type 9 wood particles distribution in PP matrix, (d) broken section appearance of 60\% (weight) Type 9 wood/PP composites.

particle contents, viscosity of composites also increased (viscosity of $60 \%$ higher than $50 \%$ ). And in the same filling fraction, the smaller-size wood particles induced relative higher viscosity in the composites. The reason could be that in the same volume, small particles will have more particle numbers than the big ones, which cause more interaction between the particles in the polymer matrix. The higher viscosity is definitely related to the higher number of particle interactions. Figure 5 shows that in both $60 \%$ (weight) contents, there are more number of particles in Type C100 wood/PP composites and Type C100 wood/PP composite has better bonding between wood particles and PP matrix.

In order to estimate the flow ability of the materials in real processing conditions, the spiral flow-testing experiments were performed in the Arburg 220s injection-molding machine. The injection pressure and injection speed are constant at $100 \mathrm{MPa}$ and $20 \mathrm{~cm}^{3} / \mathrm{s}$. The mold temperature varies at two levels $\left(35^{\circ} \mathrm{C}\right.$ and $\left.80^{\circ} \mathrm{C}\right)$; the melt temperature also changed at two levels $\left(170^{\circ} \mathrm{C}\right.$ and $\left.190^{\circ} \mathrm{C}\right)$. The flow lengths got at different processing parameters for all composites and reference PP are presented in Figure 6. Longer flow length means better flowing and processing ability of the material.

From Figure 6, it is obvious that pure PP has absolutely longer flow length than the highly filled wood/PP composites. C100/PP composites always have better flow ability than Type9/PP composites; even by rheological testing results, the former have higher viscosity than the latter. This phenomenon provided substantial proof that the rheological viscosity test data cannot precisely describe the materials' flow ability in real processing conditions, since during the real-process cycle, there are still other factors related to the flowing and processing ability of materials, such as the materials' thermal conductivity, 


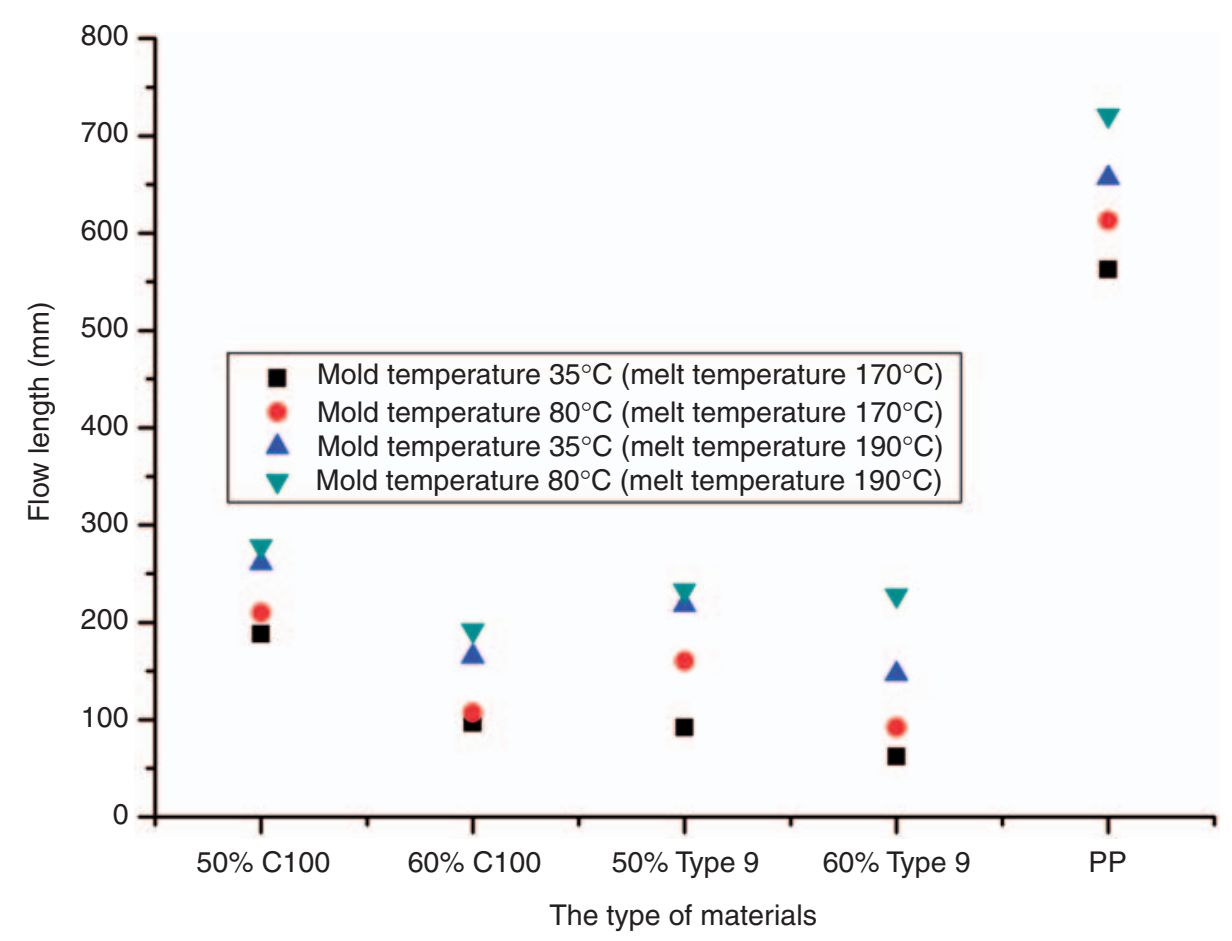

Figure 6. The spiral flow length of the materials in different injection molding process conditions.

mold-cavity structure, and thickness. Therefore, in practice, to assess the flow and forming ability of materials, it is better to use the spiral flow mold which is closer to real production conditions. Figure 6 also reveals the correlation between mold, melt temperature, and flow length. For all materials, wood/PP and pure PP, higher mold and melt temperature corresponds to longer flow length. The melt temperature has a more impressive effect on the flow length than the mold temperature.

\section{Thermal Properties}

\section{DSC ANALYSIS}

The thermal properties of the melting temperature $\left(T_{m}\right)$, the degree of crystalline, and the temperature of crystallization peak $\left(T_{c}\right)$ for pure PP and all wood/PP composites were measured by DSC method. The specimens were processed in DSC instrument by a heat-cool-heat cycle. The first heating round starts from $95^{\circ} \mathrm{C}$ to $200^{\circ} \mathrm{C}$ at a rate of $5^{\circ} \mathrm{C} / \mathrm{min}$, and then at the same rate, the cooling round comes down to $85^{\circ} \mathrm{C}$ to trace the crystallization process.

After that, they were heated up to $200^{\circ} \mathrm{C}$ again to record their melting behaviors. Table 2 lists the melting temperature $\left(T_{m}\right)$, the degree of crystallinity, and the temperature of crystallization peak $\left(T_{c}\right)$ of PP and its highly filled composites based on the DSC measuring curves.

From the results in Table 2, it is clear that the melting temperatures $T_{m}$ of $\mathrm{PP} /$ wood composites are lower than those of pure PP. The possible reason for this is that the 
Table 2. The melting temperature $\left(T_{m}\right)$, the degree of crystalline and the temperature of crystallization peek $\left(T_{c}\right)$ of PP and its wood composites.

\begin{tabular}{lccc}
\hline & $\boldsymbol{T}_{\boldsymbol{m}}\left({ }^{\circ} \mathbf{C}\right)$ & $\boldsymbol{T}_{\boldsymbol{c}}\left({ }^{\circ} \mathbf{C}\right)$ & $\begin{array}{c}\text { Degree of } \\
\text { crystalline(\%) }\end{array}$ \\
\hline PP & 169.36 & 131.15 & 46.32 \\
C100 50\% & 165.61 & 119.26 & 23.48 \\
C100 60\% & 164.36 & 121.29 & 22.75 \\
Type 9 50\% & 166.44 & 121.07 & 21.33 \\
Type 9 60\% & 165.51 & 122.43 & 20.92 \\
\hline
\end{tabular}

polymer chain in wood/PP composites are relative smaller than in pure PP because the wood particles restrict formation of a large polymer chain and make them smaller ones, which in turn decreases the melting temperature of the materials. The effects of wood particle content and size on $T_{m}$ were derived from the results, which show that for the same type of wood particle, higher content leads to lower melting temperature because more particles in matrix polymer will make the polymer chain smaller, resulting in lower melting temperature; when wood particle fraction is constant, smaller particles contributes to lower melting temperature, which could be explained by the fact that at same weight content, the small particle corresponds to more particle numbers. This makes the polymer chain in the composites smaller and melt at a lower temperature.

The degree of crystalline wood/PP composites is much lower than pure PP due to particles' restriction to crystal-structure growth, leading the filled particles to slow down the crystallization rate of the composites. The $T_{c}$ of composites is lower than pure PP, which may be the reason why the wood particles could be the crystal core to help the polymer molecule chain to easily start crystallization, but only small crystal structures are grown.

As for the relation between particles fraction and the degrees of crystalline and $T_{c}$ of wood/PP composites, increasing particle fraction results in lower degree of crystallinity but higher $T_{c}$. The reason for this may be due to the possibility that the higher the particle fraction, the more restriction for crystal structures to form, resulting in lower $T_{c}$. While higher particle fraction means more particles existing in the polymer matrix, it helps to get more crystal structures surround the particle cores.

\section{Mechanical Property}

\section{TENSILE TEST}

The tensile samples were prepared according to the injection molding process and tests were performed with a load cell of $2.5 \mathrm{kN}$ and $2 \mathrm{~mm} / \mathrm{min}$ tensile speed. Figure 7 shows the test results about E modulus, tensile strength, and breaking strength of all materials. From the figure, it can be seen that with the wood particles filling, E modulus of PP dramatically increased and higher concentration leads to higher E modulus, tensile strength, and breaking strength. However, in same filler contents, wood particle Type 9 has better effects on E modulus than Type C100. This could be explained by the fact that with bigger particle size of Type9, it is easier to get the load transferring from polymer matrix during the test and therefore has better stiffness. Whereas for tensile strength and breaking strength testing results, Type C100 provided a stronger function than 


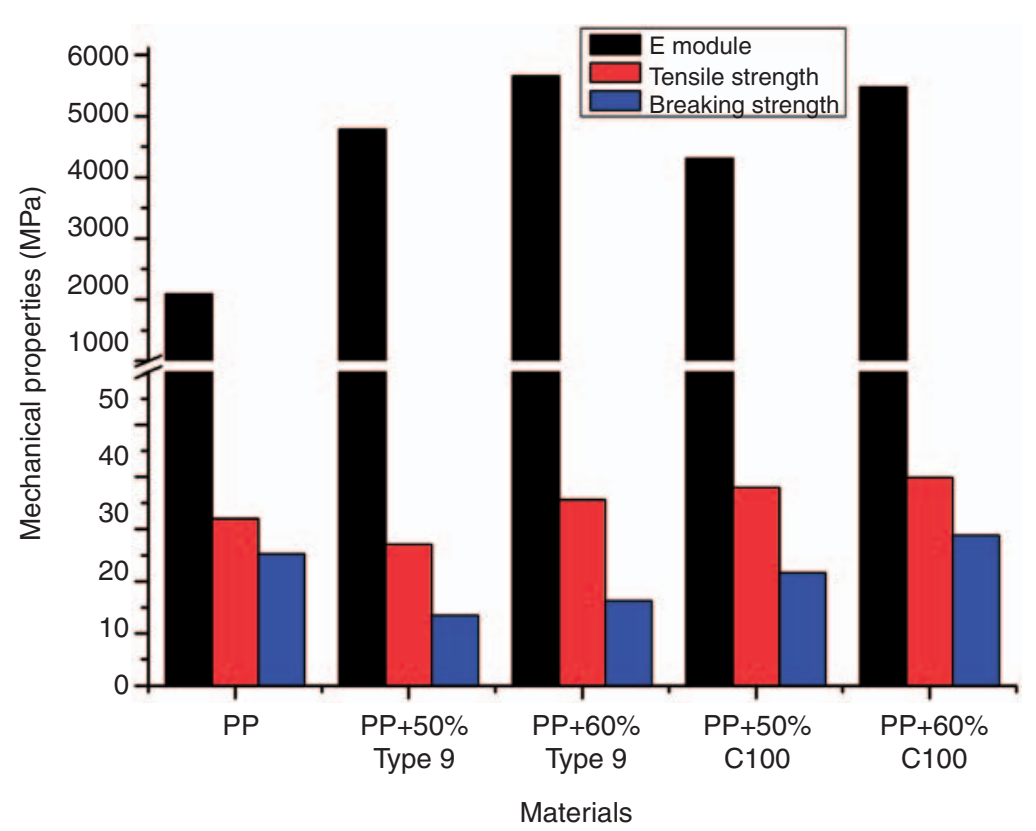

Figure 7. Mechanical properties of materials by tensile test.

Type 9, which is because in same weight filler contents, smaller particles allow more polymeric contact and it is helpful for the composite in showing better plastic deformation during the test.

\section{WELD-LINE EFFECTS}

The weld-line strength of wood/PP composites were also measured by the tensile test. The relation and comparison of mechanical properties of composites between samples with weld lines and without weld lines were made. During the tests, there was no yield behavior for all wood/PP composites samples with weld line, which means the wood composites with weld line lost main plastic deforming ability. So the results show nothing for the breaking strength of weld line with these wood/PP composites. Figure 8 shows that E modulus of weld-line samples increased with wood particle concentration for both particle types. And in same contents, composites made of Type C100 showed higher weld line E modulus than Type 9, which is converse in the results of the sample without weld line. This may be explained by the fact that due to the bigger size, Type 9 particles cannot be well entangled and distributed in weld-line area by the driving of melt flow in injection molding. On the contrary, Type C100 particles have better chance under the same conditions since they are relatively small. This also could explain the weld line tensile strength test results of wood/PP composites shown in Figure 9. The influence of particle contents on E modulus of sample with weld lines is lower than that on the sample without weld lines.

However, compared with the relation between weld line E modulus and filler contents, there is a difference in Figure 8 in the relation between weld-line tensile strength and filler contents. For both wood particle types, $60 \%$ particles content induced lower weld line 


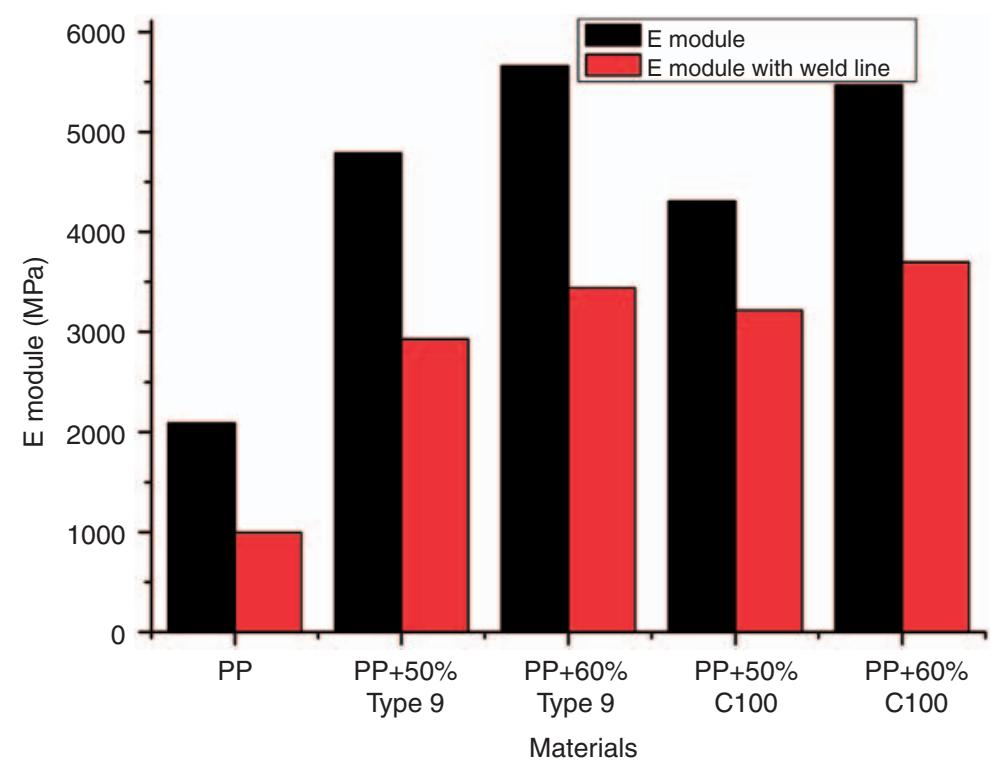

Figure 8. E module of samples with and without weld lines.

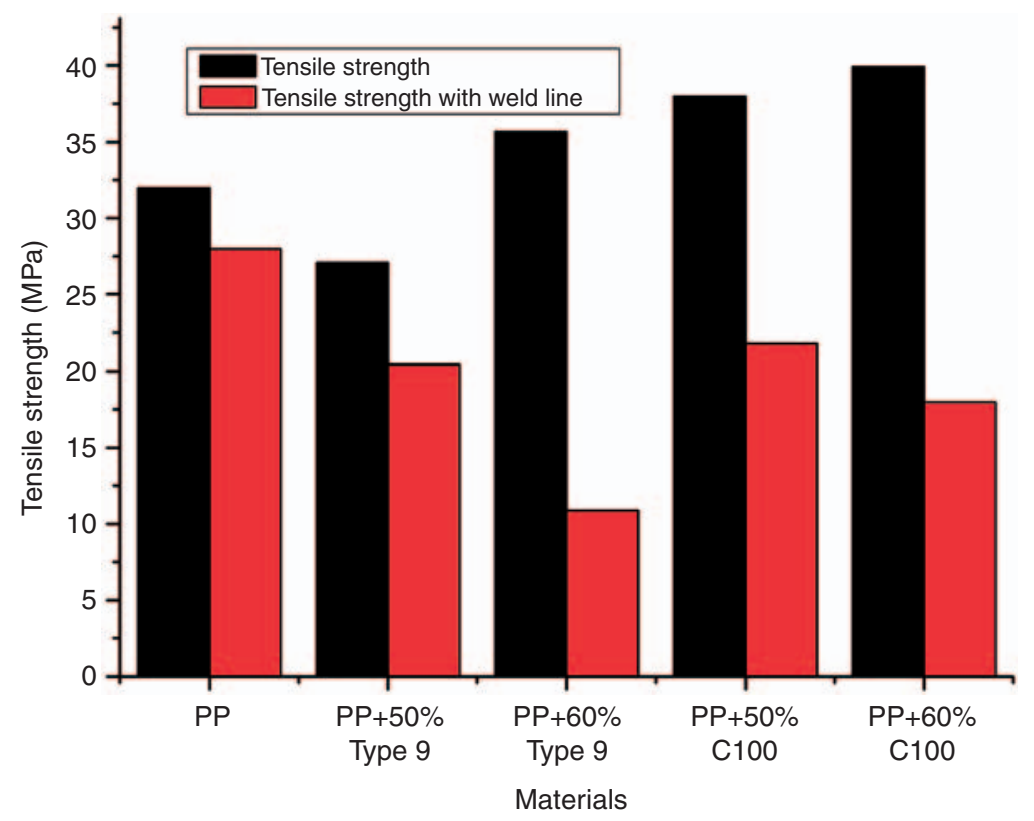

Figure 9. Tensile strength of samples with and without weld lines.

tensile strength than $50 \%$. It could be explained that in highly filled wood particle fraction (higher than $60 \%$ ), in weld-line area, there are more particle connections than in the polymers, and thereby more chance for particles to be unevenly distributed, which contributes to lower tensile deformation. 


\section{CONCLUSIONS}

Two kinds of wood particles were compounded separately in $50 \%$ and $60 \%$ weight contents with PP by extrusion machine. And based on the analysis of the results from the experiments and tests above, some conclusions can be drawn about the effects of particle concentration and type on flow ability, thermal property, mechanical property, and weld-line strength of wood particle reinforced PP composites:

(1) Two estimation methods, the rheometer and the spiral flow mold, for the flow ability of the composites were employed. Both of them indicate that in highly filled level, wood particles produce an obvious impact on the flow ability of wood/PP composites. Increasing the particle concentration leads to poor flow ability. However for relation between particle size and flow ability, spiral flow mold testing results do not coincide with that of rheological tests. In the former's results, the small-size wood particle composites correspond to better flow ability, while the rheological tests show the converse. Furthermore, effects of mold temperature and melt temperature on flow ability were also studied by the spiral flow mold, which indicates that both the temperature-related parameters influenced the composites flow ability positively and that melt temperature has more impressive effects.

(2) DSC measurements were performed and results declared that when filler contents and size increased, the melting temperature, thermal stability, and crystalline degree of composites decrease; on the contrary, the temperature of crystallization peak $\left(T_{c}\right)$ decreases.

(3) Tensile tests were carried out to assess the mechanical property of the wood/PP composites, which showed that with the wood particle filled, E modulus of wood/ PP composites was dramatically enhanced than in the original PP. The composites with higher wood particle contents have better reinforced E modulus, tensile strength, and breaking strength. When contents are constant, wood particles of big size contribute to higher $\mathrm{E}$ modulus, and ones of smaller size contribute to better tensile strength and breaking strength.

(4) Weld-line strengths of all composites were also investigated in the same way as a part of tensile tests. The results show that the usual defect of weld line in injection-molding process has a significant negative influence on the mechanical properties of wood composites. E modulus of weld-line samples increased with higher wood particle concentrations for both particle types, but tensile strength decreased. And smaller size particles produced higher E modulus and tensile strength.

\section{ACKNOWLEDGMENT}

The authors would like to thank DFG (Deutsche-Forschungsgemeinschaft) for the financial support of the investigation.

\section{REFERENCES}

1. Park, B. D. and Balatinecz, J. J. (1997). A Comparison of Compounding Processes for Woodfiber/ Thermoplastic Composites, Polymer Composites, 18(3): 425-431. 
2. PARK, B. D. and Balatinecz, J. J. (1997). Mechanical Properties of Wood-fiber/Toughened lsotactic Polypropylene Composites, Polymer Composites, 18(1): 80-89.

3. Beshay, A. D., Kokta, B. V. and Daneault, C. (1985). Use of Wood Fibers in Thermoplastic Composites II Polyethylene, Polymer Composites, 6(4): 261-271.

4. Kokta, B. V., Chen, R., Daneault, C. and Valade, J. L. (1983). Use of Wood Fibers in Thermoplastic Composites, Polymer Composites, 4(4): 229-232.

5. Selke, S. E. and Wichman, I. (2004). Wood Fiber Polyolefin Composites, Composites: Part A, 35: $321-326$.

6. Bledzki, A. K. and Gassan, J. (1999). Composites Reinforced with Cellulose Based Fibers, Progress in Polymer Science, 24: 221-274.

7. Zaini, M. J., Fuad, M., Ismail, Z., Mansor, M. S. and Mustafah, J. (1996). The Effect of Filler Content and Size on the Mechanical Properties of Polypropylene/Oil Palm Wood Flour Composites, Polymer International, 40: 51-55.

8. Ismail, H., Rozman, H. D., Jaffri, R. M. and Ishak, Z. A. (1997). Oil Palm-wood Flour Reinforced Epoxidized Natural Rubber Composites: The Effect of Filler Content and Size, European Polymer Journal, 33: 1627-1632.

9. Gupta, B. S., Reiniati, I. and Laborie, M.-P.-G. (2007). Surface Properties and Adhesion of Wood Fiber Reinforced Thermoplastic Composites, Colloids Surfaces A: Physicochemical Engineering Aspects, 302(1): $388-395$

10. Lundquist, L., Marque, B., Hagstrand, P. O., Leterrier, Y. and Manson, J. A. E. (2003). The Curves of Wood Powder/Polypropylene Composites with ..., Composites Science Technology, 63: 137-152.

11. Eckert, C. (2000). Opportunities for Natural Fibers in Plastic Composites, In: Proceedings of Progress in Wood Fibre-Plastic Composites, 25-26 May, Toronto, ON, Canada.

12. Pritchard, G. (2004). Two Technologies Merge: Wood Plastic Composites, Plastics, Additive Compound, 6(4): $18-21$.

13. Chen, Y., Sun, L., Chiparus, O., Negulescu, I., Yachmenev, V. and Warnock, M. (2005). Kenaf/Ramie Composite for Automotive Headliner, Journal of Enviromental Polymer, 13(3): 107-114.

14. Rouilly, A., Orliac, O., Silvestre, F. and Rigal, L. (2006). New natural Injection-Moldable Composite Material from Sunflower Oil Cake, Bioresource Technology, 97(4): 553-561.

15. Zampaloni, M., Pourboghrat, F., Yankovich, S. A., Rodgers, B. N., Moore, J., Drzal, L. T., Mohanty, A. K. and Misra, M. (2007). Kenaf Natural Fiber... Problems and Solutions, Composites: Part A, 38: 1569-1580.

16. Lyons, J. S. and Ahmed, M. R. (2005). Factors Affecting the Bond between Polymer Composites and Wood, Journal of Reinforced Plastics and Composites, 24(4): 413-421.

17. Cantero, G., Arbelaiz, A., Mugika, F., Valea, A. and Mondragon, I. (2003). Mechanical Behavior of Wood Polypropylene Composites Effects of Fiber Treatments and Ageing Processes, Journal of Reinforced Plastics and Composites, 22(1): 37-50.

18. Kaboorani, A. and Faezipour, M. (2009). Effects of Wood Preheat Treatment on Thermal Stability of HDPE Composites, Journal of Reinforced Plastics and Composites, doi: 10.1177/0731684408094064.

19. Cui, Y. H., Tao, J., Noruziaan, B., Cheung, M. and Lee, S. (2008). DSC Analysis and Mechanical Properties of Wood Plastic Composites, Journal of Reinforced Plastics and Composites, doi: 10.1177/0731684408097766.

20. Chahamarali, M., Mirbagheri, J., Tajvidi, M., Kazemi Najafi, S. and Mirbagheri, Y. (2008). Mechanical and Physical Properties of Wood Plastic Composite Panels, Journal of Reinforced Plastics and Composites, doi: $10.1177 / 0731684408093877$.

21. Azizi, H. and Ghasemi, I. (2009). Investigation on the Dynamic Melt Rheological Properties of Polypropylene Wood Flour Composites, Polymer Composites, 30: 429-435.

22. Hristov, V. and Vlachopoulos, J. (2008). Effects of Polymer Molecular Weight and Filler Particle Size on Flow Behavior of Wood Polymer Composites, Polymer Composites, 29: 831-839.

23. Nourbakhsh, A. and Ashoriz, A. (2008). Fundamental Studies on Wood Plastic Composites Effects of Fiber Concentration and Mixing Temperature on Mechanical Property of Poplar PP Composites, Polymer Composites, 29: 569-573.

24. Migneault, S., Koubaa, A., Erchiqui, F., Chaala, A., Englund, K. and Wolcott, M. P. (2009). Effects of Processing Method and Fiber Size on the Structure and Properties of Wood Plastic Composites, Composites: Part A, 40: 80-85.

25. Beg, M. D. H. and Pickering, K. L. (2008). Reprocessing of Wood Fibre Reinforced Polypropylene Composites. Part I. Effects on Physical and Mechanical Properties, Composites: Part A, 39: 1091-1100.

26. Dominkovics, Z. and Béla Pukánszk, L. (2007). Surface Modification of Wood Flour and Its Effect on the Properties of PP Wood Composites, Composites: Part A, 38: 1893-1901. 